\title{
Synthesis of 4-Organochalcogenyl-1-H-1,2,3-Triazoles
}

\author{
Daiana M. Leal ${ }^{\star 1}(P G)$, Flávia G. Manarin ${ }^{1}(P Q)$, Hélio A. Stefani ${ }^{1}(P Q)$ \\ ${ }^{1}$ Departamento de Farmácia, Faculdade de Ciências Farmacêuticas, Universidade de São Paulo, São
}

Paulo, SP, Brasil

*daianamartinsl@usp.br

Keywords: Triazoles; Chalcogenides; Click Chemistry.

\section{INTRODUCTION}

The main goal of Click Chemistry is to develop reactions with simple conditions, wide in scope, high yields and easy product purification, in small and large scales. ${ }^{1}$ Huisgen cycloaddition, or 1,3-dipolar cycloaddition, belongs to this group of reactions, and its used to obtain a range of new five-membered heterocycle rings, including 1,2,3-triazoles, ${ }^{2}$ achieved through the cycloaddition of an azide to an alkyne.

The synthesis of 1,2,3-triazoles is very important because these substances are only obtained through organic synthesis, they are not found in nature. ${ }^{3}$ They also have several applications against many diseases like infections and epilepsy. ${ }^{4}$

In this context, parallel to the triazoles, we decided to synthesize products that contain the heterocycle ring and an atom of chalcogen. Organoselenium and organotellurium molecules have a large range of biological activity, and are often used as intermediates in organic synthesis. ${ }^{5}$

The goal of this work is the functionalization of the position 4 of the triazole ring, inserting chalcogenes in the structure, and at the end obtain a range of new structure with great possibility of biological activity.

\section{RESULTS AND DISCUSSION}

We tried to find the best condition for the cycloaddition reaction using benzyl azide as the substract for the tests, as we can see in scheme 1.

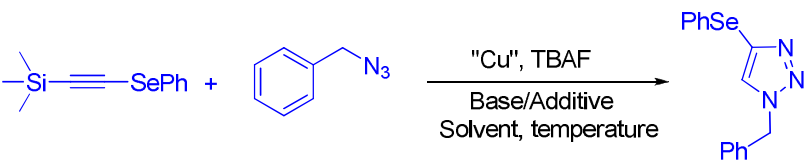

Scheme 1. General Reaction

Initially, different types of copper (I) and (II) salts, such as: Cul, $\mathrm{Cu}(\mathrm{OAc}) 2, \mathrm{CuCN}, \mathrm{CuBr}, \mathrm{CuCl}$ and CuSO4 as well as the amount necessary for the success of the reaction was investigated. The use of a catalytic amount of $\mathrm{Cu}(\mathrm{OAc})_{2}(10 \mathrm{~mol} \%)$ gave the best yields. Continuing the tests different bases such as Et3N and PMDTA, and additives such as sodium ascorbate as well as different solvents were tested: THF, MeCN, DMSO, MeOH and $\mathrm{H}_{2} \mathrm{O}$.
With the best condition in hands, we were able to produce different kinds of substituted triazoles.

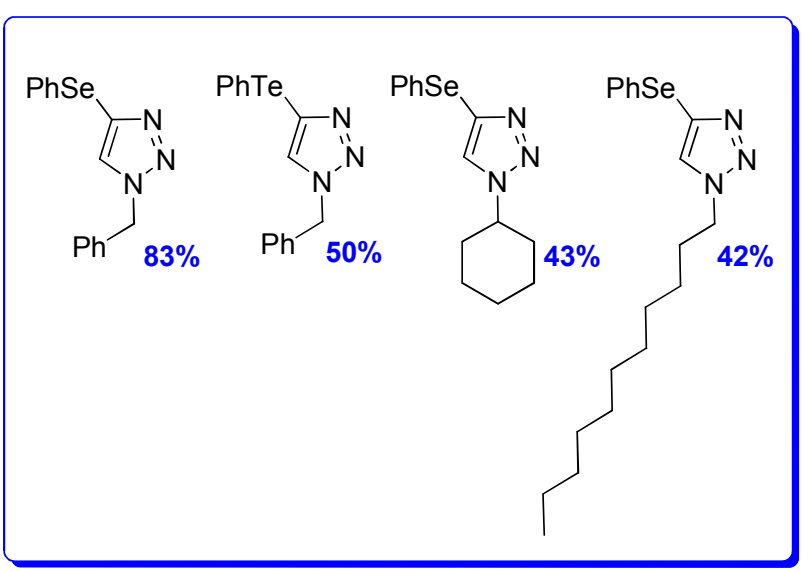

Figure 2: Some examples of the compounds synthesized.

\section{CONCLUSION}

Through the methodology previously described, it was possible to synthesize novel compounds in the literature, triazole rings containing chalcogenes in the position 4 with promising biological activities.

\section{ACKNOWLEDGEMENTS}

The authors would like to thank CNPq (155.208/2010-0) and FAPESP (2007/54904-2), (2010/15677-8).

\section{REFERENCES}

${ }^{1}$ Kolb, H.C.; Finn, M.G.; Sharpless, K.B. Angew. Chem. Int. Ed. 2001, 40, 2004.

'Lal, S.; Díez-Gonzáles, S. J. Org. Chem. 2011, 76, 2367.

${ }^{3}$ Tornol, C.W.; Christensen, C.; Meldal, M. J. Org. Chem. 2002, 67, 3057.

${ }^{4}$ Harju, K.; Vahermo, M.; Mutikainen, I.; Kauhaluoma, J.Y. J. Comb. Chem. 2003, 5, 826.

${ }^{5}$ Potapov, V.A.; Amosova, S.V. Rus. J. Org. Chem. 2003, 39, 1373. 